\title{
El yo inasible de Pascal frente a la fortaleza del sujeto cartesiano ${ }^{1}$
}

\section{Pascal's ungraspable self compared to the strength of the cartesian subject}

\author{
Alicia Villar EZCURRA
}

Universidad Pontificia Comillas

\begin{abstract}
RESUMEN. Frente a Descartes, que quiso convertir al sujeto pensante en el centro y fortalecer su poder, Pascal se confrontó con la contingencia, el azar y la opacidad de la existencia humana. Trató de «descentrar» al sujeto y ahondar en sus disonancias más profundas. Distinguió tres órdenes de realidad inconmensurables: los cuerpos, los espíritus y la caridad. En el plano moral, el «ordo amoris» representa el punto de vista absoluto al que se ordenan todos los puntos relativos. Sólo liberándose de los deseos de dominación, el ser humano accede a la verdadera justicia y bondad.
\end{abstract}

Palabras clave: Pascal, Descartes, sujeto, yo, órdenes de realidad, razón, corazón.

\section{Introducción}

El pensamiento contemporáneo ha denunciado los excesos del racionalismo moderno desde distintos frentes, convirtiendo a Descartes en el blanco preferente de los más incisivos ataques. Sin embargo, el racionalismo cartesiano fue también cuestionado en el contexto inmediato del XVII francés y de la nueva ciencia. Me refiero a Pascal que en una de sus notas sentenció: «Descartes: inútil e incierto». Con ello vaticinó la caducidad de un sistema que había nacido con vocación de perennidad.
Abstract. Compared to Descartes, who attempted to make the thinking subject the centre and strengthen its power, Pascal was confronted with the contingency, chance and opacity of human existence. He tried to «decentralise» the subject and delve further into its deepest dissonance. He classified three unmeasurable orders of reality: body, spirit and charity. On a moral level, for Pascal the «ordo amoris» represents the absolute viewpoint to which all relative points of view are ordered. Only through a release from the desire of domination can the human being discover true justice and goodness.

Key words: Pascal, Descartes, subject, self, orders of reality, reason, heart.

La postura de Pascal, un genio de la Historia de la Ciencia, supone el cuestionamiento del cientificismo posterior $y$ también un intento de articular la razón y la fe. Como indicó Karl Jaspers, a la vista del desarrollo posterior del racionalismo, su pensamiento adquiere veracidad y profundidad. Sin forjar un sistema filosófico cerrado cabe preguntarse si Pascal puede ser un pensador para tiempos de crisis como los nuestros ${ }^{2}$.

Las concepciones de Descartes y Pascal difieren en el plano de las ciencias y de la filosofía, pero sobre todo compro- 
baremos que su «pathos existencial» es bien distinto.

Son muchos los fragmentos que contrastan con los planteamientos del racionalismo cartesiano y son bien conocidas las diferencias entre las demostraciones racionales de la existencia de Dios de Descartes y el argumento de la apuesta de Pascal o su distinción del espíritu de geometría y de l'ésprit de finesse. Pero incidiré en otros fragmentos de Pascal, menos conocidos y en los que también se comprueba la actualidad de su dialéctica con el racionalismo. Además, se refieren a puntos esenciales del cartesianismo: el conocimiento de la naturaleza del yo y los distintos órdenes de realidad.

\section{El encuentro de Pascal con Descartes}

La oposición de Descartes y Pascal se ha convertido en simbólica y se suma a las antítesis frecuentes entre los clásicos franceses: Corneille y Racine, Voltaire y Rousseau, etc. A este respecto, y para evitar las simplificaciones que los simbolismos comportan es preciso distinguir dos puntos de vista: el del parentesco espiritual y el de la influencia ${ }^{3}$. En el caso de Descartes y Pascal, representan dos modos distintos de ser científico, de filosofar y de vivir el cristianismo. Sin embargo, no hay que olvidar que el cartesianismo estaba muy presente en el ambiente intelectual en el que Etienne Pascal introdujo a su hijo desde muy joven. En el mismo vocabulario de Pascal se puede reconocer la impronta de Descartes a quien consideraba un contemporáneo capital.

Descartes y Pascal se conocieron personalmente y conversaron en dos ocasiones, el veinticuatro y el veinticinco de septiembre de 1647, a iniciativa de Descartes, de paso por París ${ }^{4}$. El joven Pascal, era entonces un prometedor científico conocido por su invento de la máquina aritmética, la «pascaline». Pero Descar- tes se interesó sobre todo por el problema de la existencia del vacío que Pascal investigaba desde $1646^{5}$.

En los Pensamientos el nombre de Descartes aparece tres veces en los fragmentos: L. 84, L. 553, y L. $887^{6}$. Además, en las «Frases atribuidas a Pascal» se incluyen varios fragmentos que se refieren expresamente a Descartes o bien a la filosofía cartesiana: L. 1001, L. 1005 y L. 1008. En todos ellos, se realiza una critica abierta de las pretensiones cartesianas, que se resume en el fragmento más célebre: «Descartes. Inútil e incierto» (L. 887) 7 .

Inútil e incierto son calificativos que aparecen también en el L. 84: «Descartes. Hay que decir en líneas generales: esto se hace por figura y movimiento. Porque esto es verdad, pero decir cuáles y disponer la máquina es ridículo. Porque es inútil, e incierto, y penoso. Y aunque fuera verdad, no considero que toda la filosofía valga una hora de esfuerzo». La inutilidad de dicha filosofía explica el propósito que se recoge en el fragmento L. 553: «Escribir contra los que profundizan demasiado en las ciencias. Descartes».

En resumen, las distintas alusiones de Pascal a Descartes, se refieren preferentemente a las pretensiones de su física o filosofía natural, salvo la mención expresa de su metafísica en el fragmento L. 1001, una opinión recogida por su sobrina y biógrafa Margarita Périer: «No puedo perdonar a Descartes: hubiera querido, en toda la filosofía, poder prescindir de Dios; pero no ha podido evitar para poner el mundo en movimiento, hacer que le diese un capirotazo; después de esto ya no necesita a Dios para nada». La crítica al Deus ex machina resulta manifiesta.

Asimismo, se pueden encontrar referencias implícitas a los ideales cartesianos, en varios fragmentos dedicados a la 
vanidad de las aspiraciones de los filósofos y de los sabios, en los que se enfrenta a su soberbia y dogmatismo.

\section{Cuestiones relativas a las ciencias y al método}

En el siglo XVII, el debate sobre las diversas concepciones de la nueva ciencia y del conocimiento, se ejemplifica en la oposición entre las posturas de Pascal y Descartes.

Si se analizan los distintos trabajos científicos ${ }^{8}$ de Pascal, y de acuerdo con Catherine Chevalley ${ }^{9}$, se comprueba que su obra constituye no sólo una alternativa coherente en el dominio de la teoría del conocimiento, sino también un intento global de pensar la contingencia e introducir una racionalidad de lo probable. Para Pascal la naturaleza no obedece a leyes universales y necesarias, sino que es un proceso sometido a fluctuaciones. El conocimiento tampoco es un saber neutro e independiente de su objeto, sino relativo a sus propias condiciones de enunciación. Dicha sensibilidad resulta de una enorme actualidad.

Mientras que Descartes excluye todo lo que es verosímil del campo de nuestros conocimientos y trata de fundar la física en la metafísica, para salvarla del riesgo de la incertidumbre, Pascal no excluyó nunca la contingencia y se atrevió a pensar lo que inicialmente parecía impensable. No buscó deducir de la metafísica ${ }^{10}$ o a partir de principios abstractos la solución de problemas dispares, sino que procedió de forma inversa. Diseñó un método adecuado para cada una de las dificultades específicas con las que se confrontaba. Pueden citarse como ejemplos sus trabajos científicos sobre «la geometría del azar», el cálculo del infinito, o sus experimentos sobre la existencia del vacío. Por este motivo, Pascal supuso una de las alternativas más fuertes al cartesianismo. Distinguió la pluralidad de pla- nos, perspectivas y métodos, y se esforzó por pensar las distintas racionalidades que en cada caso resultan de aplicación. Los desafíos que plantean el mundo contemporáneo quizá aconsejan esta misma actitud.

\section{El método y el espíritu geométrico}

En su opúsculo Sobre el espíritu geométrico, una suerte de Discurso del método, Pascal resumió los fundamentos de su método geométrico que consiste en progresar por definiciones, principios (axiomas) y demostraciones. Admite que el método perfecto, que consistiría en definirlo y demostrarlo todo, es imposible, pues los primeros términos que se quisieran definir supondrían otros anteriores para servir a su explicación, y así hasta el infinito. Lo mismo ocurriría con las primeras proposiciones.

Precisa que la geometría es «casi» - la única de las ciencias humanas que produce demostraciones infalibles porque observa el verdadero método-. De ahí, la conclusión de Pascal: aquello que sobrepasa a la geometría nos sobrepasa en realidad. Hasta aquí parece coincidir con Descartes. Pero al final del opúsculo, Pascal advierte que la misma geometría nos sitúa ante ideas como la de infinito, referido al movimiento, al número, al espacio extenso y al tiempo, que abre la mente humana a la consideración de «otras maravillas». Permite que el ser humano se estime en su justo precio. Esta apertura y capacidad para lo infinito nunca podrá ser colmada por ciencia alguna.

En resumen, para Descartes la metafísica es necesaria para consagrarse después a la ciencia. Para Pascal, por el contrario, la ciencia puede conducir al ser humano a cuestionarse sobre otros enigmas. El progreso de las ciencias nunca nos dará un saber total, ni es el referente último. Descubren verdades parciales, no verdades últimas. 
Con ello, Pascal destruye el vínculo que Descartes había establecido entre geometría y teoría del conocimiento y se opone a la idea de derivar toda una teoría general del conocimiento de la evidencia excepcional del objeto matemático. El ser humano se mueve también por probabilidades y cuando busca el sentido y fin de las cosas necesita algo más que espíritu geométrico.

\section{La articulación de la razón y el corazón}

Descartes y Pascal distinguen los conocimientos intuitivos y los discursivos, pero mientras que para Descartes son operaciones intelectuales, para Pascal la razón sólo demuestra y deduce a partir de principios que son intuidos, sentidos por el corazón.

El corazón capta de un modo inmediato los fundamentos de las verdades matemáticas. Sus conocimientos son más firmes que los que nos proporcionan nuestros razonamientos que tienen que apoyarse en ellos. La razón deduce y demuestra. Es la facultad de las reglas; el corazón de los principios. Sus funciones son complementarias. La razón conduce a definiciones precisas y comunicables. El corazón pertenece a lo individual y es difícil explicar a otro lo que uno siente.

Como es sabido, para Pascal los conocimientos esenciales del corazón tienen un doble papel. Por una parte, constituyen el punto de partida de todas las ciencias; por otra, impulsan las decisiones morales y descubren los problemas vitales que son esenciales. El corazón representa la profundidad y la espontaneidad, nuestro fondo indiferenciado $\mathrm{y}$ ser verdadero, que accede a las verdades últimas.

Pascal recupera la importancia del corazón, secularmente olvidada por la filosofía occidental, órgano de la energía vital, raíz y centro de la persona. No hay aquí resonancias románticas. Como el corazón bíblico representa el dinamismo interior en la multiplicidad de sus actos, sin que haya una separación clara entre lo corporal y lo espiritual. El corazón valora las cosas que tienen una importancia decisiva y de acuerdo con ello ordena su vida. Es la raíz de la actividad espiritual que aporta los fundamentos al saber y los motivos a la acción. Es el centro de la afectividad y el principio de la voluntad humana, la raíz de la actividad pensante. Es aquello que puede orientar a lo infinito $\mathrm{y}$ a lo eterno.

Científico comprometido con la búsqueda de la verdad, Pascal advirtió del peligro de extralimitar las propias fronteras del saber y anular otro tipo de conocimientos. Es lo que recogerá en uno de los fragmentos de los Pensamientos: "Escribir contra los que profundizan demasiado en las ciencias». Pascal es consciente de que la geometría es uno de los oficios probablemente más bellos del mundo, pero tan sólo un oficio, como precisará en su carta a Fermat de 1660. Nunca podrá consolar en tiempos de aflicción. El hombre que hay detrás del científico necesita una verdad integral.

Se comprueba que la epistemología de Pascal y Descartes son distintas, y también su antropología, como veremos seguidamente. Pascal siempre se confronta con la contingencia, el azar y la opacidad de la existencia humana. Es lo que hace que filósofos contemporáneos tan distintos como Clémont Rosset, Pierre Bordeau, Comte Sponville o Vattimo hayan citado y recuperado a Pascal de modos muy distintos.

\section{Visión de la condición humana $y$ de la relación con Dios}

En los Pensamientos converge la experiencia científica, mundana y religiosa de Pascal. Es una obra mucho más difícil de lo que se piensa y no es sencillo guiarse 
en ese millar de fragmentos que se encontraron tras su muerte. Su lectura exige un ejercicio interpretativo constante. Esto quizá explica que Pascal haya sido calificado como escéptico o místico, misántropo o humanista, ortodoxo o heterodoxo, antirracionalista o racionalista. Por tanto, cabe preguntarse aún si ha sido realmente comprendido. En los Pensamientos, Pascal tampoco renuncia a la razón, sólo a su abuso en varios dominios ${ }^{11}$.

El primero es la ética. A diferencia de Descartes y los racionalistas posteriores, Pascal considera que la razón, por sí sola, es incapaz de fundar sólidamente el actuar humano. La diversidad asombrosa de costumbres, una segunda naturaleza, echa por tierra tal pretensión. Exclama con Montaigne: «iverdad allende los Pirineos!».

Es imposible que el ser humano, por sí mismo, controle racional y perfectamente sus pasiones, lo que le sitúa lejos del ideal estoico cartesiano descrito en el Tratado de las pasiones. A juicio de Pascal, como dirá al hablar de los estoicos, esta actitud no revela más que soberbia y engaño. Desde el punto de vista humano, sin la ayuda de Dios, sólo podemos aspirar a lo que llama «moral del hombre honesto», una ética de mínimos que está lejos del máximo moral: la santidad o el heroísmo moral. Para ello se requiere el orden del amor o de la caridad, orden distinto al orden racional.

En segundo lugar, para Pascal la razón no tiene fuerza suficiente para conducirnos de un modo permanente a demostrar la existencia de Dios. Distingue las certezas teóricas de las certezas morales o prácticas. Creer no es demostrar es confiar y arriesgar. Como después Kant, para Pascal la razón puede demostrar tanto que Dios existe y el alma es inmortal como su contrario ${ }^{12}$. No hay datos suficientes para concluir ni una presencia manifiesta de Dios, ni una exclusión total.
Lejos del racionalismo de Descartes, pero también del difuso fideísmo de Montaigne, Pascal evoca al Dios oculto, un clásico de la literatura espiritual. En el Deus absconditus Pascal verá no sólo el principal fundamento del cristianismo, sino también la mayor prueba de su sentido. El Dios de los cristianos es el «Dios de Abraham, de Isaac y Jacob (Memorial): un Dios de amor y consuelo (L. 449), algo más que el Dios autor de los elementos, del que hablan algunos filósofos.

¿Supone eso que Pascal se abandone al pirronismo o fideísmo? De ningún modo. De lo contrario no se explicaría su propósito de escribir una apología de la religión cristiana ${ }^{13}$.

A diferencia de Descartes, Pascal no deja «aparte las verdades de fe» y se compromete a fondo con lo que resulta importante en la vida. En su caso, la experiencia científica y mundana le hizo presentir el avance del agnosticismo en los ambientes humanistas y libertinos de su tiempo y estima urgente dar razón de las creencias para distinguirlas del fanatismo y la superstición. En este sentido, considera que el análisis de la condición humana y de la historia, lo que hoy llamaríamos ciencias humanas, puede hacer creíble a la fe cristiana ${ }^{14}$. Así, en la experiencia de la religión cristiana, quiso encontrar el punto de apoyo que da al hombre sentido último. Para ello, no recurre a demostrar sino a argumentar, sugerir $\mathrm{y}$ persuadir.

Alejándose de la Escolástica, Pascal aspiraba a formular un nuevo ${ }^{15}$ discurso teológico y moral sobre el ser humano que no olvida sus fuentes originarias. $\mathrm{Su}$ originalidad consiste en actualizar temas que provienen de las Escrituras y de la tradición agustiniana, dialogando con los retos que planteaba su tiempo, y en ocasiones con las filosofías de Montaigne y Descartes. 
Así, analiza las contradicciones del mundo moderno, desde categorías como la vanidad humana, la idolatría, el corazón de carne y el de piedra, o la ceguera para descubrir un Dios que se esconde ${ }^{16}$. Sus descripciones sobre ese caos asombroso que es el hombre, tratarán de despertar el interés por plantearse las verdades esenciales, las vitales, y experimentar la necesidad de la apertura a la Trascendencia. Su método es inductivo, más que deductivo y abunda en ejemplos que toma de la vida de su tiempo. Tiende siempre a abordar los problemas de forma concreta, en «situación», no de un modo abstracto.

\section{El descentramiento del sujeto}

Si Descartes quiere convertir al sujeto pensante en el punto de Arquímedes y fortalecer su poder, Pascal, que reconoce también la grandeza del pensamiento, se dirige a descentrar al «sujeto». Si en Descartes abundan los símiles tomados de la construcción y la arquitectura (voluntad de construir nuevos cimientos, trazado y diseño de ciudades, la casa en la que se va a habitar) que simbolizan la solidez y la seguridad de la nueva filosofía, en Pascal se repiten las referencias al elemento líquido, inconsistente e inasible (flotamos, vagamos). Advierte: Glissez mortels, n'appuyez pas... Es lo que expresa en su fragmento en los que alude a los ríos de Babilonia, un pasaje de un Salmo evocado también por San Juan de la Cruz, símbolo de lo perecedero y efímero. Nos dice: «Sobre los ríos de Babilonia (L. 545), ahí es donde estamos apoyados...». Super flumina Babylonis ${ }^{17}$.

Los tres ríos representan las tres concupiscencias que arrastran al hombre y provocan su deriva. Se manifiestan en las sectas filosóficas. La libido dominandi en el estoico que se esfuerza en gobernarse a sí mismo. La libido sciendi en el académico que busca la serenidad en el puro conocimiento ${ }^{18}$. La libido sentiendi en el epicúreo que busca la felicidad en el puro disfrute. Son ejemplos de Escuelas filosóficas que creen acceder a la sabiduría cuando en realidad sólo son gobernadas por una pasión dominante.

Pascal parece conocer muy bien las ilusiones a las que uno se expone al abandonarse a la pura introspección. Busca evitar los excesos del pirronismo y el dogmatismo. Creyendo conocerse, el sujeto no advierte las profundas distorsiones que proyecta en todo lo que trata de explorar.

Si a Descartes le interesa la unidad, el orden de la razón y la cohesión, Pascal ahonda en las disonancias, el desorden, las contradicciones, las paradojas y tensiones de la existencia. Como Schopenhauer, es implacable cuando habla de la condición humana. Existir auténticamente es experimentar el abismo de la miseria, la incertidumbre, la inseguridad, el desencanto, el desamparo y el desasosiego. Situación de la que uno se evade por medio de la diversión y otros mecanismos de evasión.

Vanidad tiene para Pascal un sentido amplio y complejo. Significa inanidad, vacío, inconsistencia, insustancialidad. Se contrapone al ser. Es la apariencia o imagen que toma el lugar de la realidad, un enigma similar al que había explorado en la naturaleza. Vanidad se asocia con autoengaño y califica a un corazón vacío de bienes sustanciales que invierte el valor real de las cosas y concede importancia a lo que no lo tiene. Es banal, prisionero de la superficie. Al igual que Unamuno, Pascal se escandaliza de que el ser humano pueda vivir sin preguntarse por su destino mortal y se concentre en lo superfluo.

Si al hablar de la «Vanidad» Pascal muestra que el hombre se deja arrastrar por las apariencias y la falsedad, al hablar de la «Miseria» advierte que la toma de 
conciencia de la vanidad y de la incapacidad para alcanzar la verdadera justicia y la virtud plena, es dolorosa. Miseria es para Pascal indigencia, fragilidad, infortunio. Por eso cita a Job, a su juicio quien mejor ha hablado de la desdicha.

En suma, Pascal describe en sus Pensamientos a un hombre escindido, lábil y fragmentado. Es un monstruo incomprensible. Su grandeza, el pensamiento, no es sino conciencia de fragilidad y desdicha. La lucidez, por su parte, la experiencia del dolor propio asumido, se convierte en factor de dignificación personal.

Pascal quiere poner de manifiesto que cuando el hombre no busca su arraigo en Dios, puede erigir otros absolutos que le esclavizan sin ser consciente de ello. Cuando trata de evadirse de mil formas, se hunde más en el infortunio. Por ello se burla abiertamente de aquellos que creen encontrar un asiento firme y edifican una «torre que se eleva al infinito», imagen que, como la torre de Babel, simboliza la vanidad y fracaso de tal empresa. Creyendo elevarse, el ser humano no hace más que agravar la altura de su caída. El fundamento que se creía firme cruje, y la tierra se abre hasta los abismos (L. 199). Los fragmentos más dramáticos de Pascal se destinan a mostrar que la seguridad y el éxito aparente pueden ser un factor de deshumanización.

\section{Un yo inasible e inconsistente}

Las críticas de Pascal a las pretensiones de científicos y filósofos se contemplan bajo el prisma de la categoría de la vanidad y de la idolatría. De ahí que califique como vanas las aspiraciones de alcanzar una verdad plena y absoluta de filósofos y científicos. Piensa que muchos sabios caen en la idolatría y se engañan sobre el alcance real de sus descubrimientos: no son más que pequeños avances, referidos a verdades puntuales y particulares que nunca podrán sustituir a la búsqueda de sentido de la existencia.

El mismo proyecto de conocer racionalmente con claridad y distinción qué es el yo, el nuevo pilar de la filosofía moderna, el punto de apoyo de Arquímedes, se revela para Pascal confuso. No está seguro de saber en qué consiste la esencia de eso que se llama «yo» y advierte de los peligros del ensimismamiento.

En el fragmento L. 688, donde Pascal indaga qué es el yo, la problemática cartesiana aparece bajo una nueva luz. Detengámonos ahora en este corto y denso fragmento, calificado como aporético ${ }^{19}$ :

«¿Qué es el yo? Un hombre que se asoma a la ventana a ver a los que pasan; si yo paso por ahí, ¿puedo decir que está allí para verme? No, porque no piensa en mí en particular. Y aquél que ama a alguien a causa de su belleza, ¿le ama? No, pues la viruela que matará su belleza sin matar a la persona, hará que deje de amarle. Y si se me quiere por mi inteligencia, por mi memoria, ¿se me quiere? ¿A mí? No, pues puedo perder esas cualidades sin perder mi yo. Por tanto, ¿dónde está ese «yo» que no está ni en el cuerpo, ni en el alma?, y ¿cómo amar al cuerpo o al alma, sino por sus cualidades, que no son lo que constituyen el yo, puesto que son perecederas? Pues, ¿se amaría la sustancia del alma, de una persona abstractamente y fueran cuales fueran las cualidades que tuviera? Eso no es posible y sería injusto. ...».

El inicio del fragmento recuerda a la segunda Meditación de Descartes. La puesta en escena es muy similar: la ventana, la observación, incluso los hombres que pasean ${ }^{20}$. Pascal parece situarse en la perspectiva del observador que indaga la naturaleza del objeto observado. Ahora bien, a pesar de las similitudes, las diferencias son notables. Si la búsqueda de la claridad y distinción parecen presidir las reflexiones cartesianas sobre el sujeto, los fragmentos de Pascal al respecto recogen la experiencia de desconcierto. 
En primer lugar, no se pregunta como Descartes «¿quién soy yo?»o «¿qué soy?» ${ }^{21}$, sino ¿qué es el yo? (le moi). Recordemos que para Pascal, se puede conocer la existencia de una cosa, sin conocer su naturaleza (L. 418). Pero además, la perspectiva del observador que se asoma a la ventana y que aparece al final de la segunda Meditación es precisamente la contraria a la de Descartes. En el caso de Descartes, soy yo quien miro por la ventana al paseante; en el caso de Pascal, soy yo el que soy observado desde la ventana. El yo como objeto de definición es sustituido por el yo como objeto de la mirada de otro.

A mi juicio, lo más llamativo de este texto es que revela los diferentes intereses de Descartes y Pascal. El interés de Descartes es evidenciar que la percepción es un juicio de la razón. Es lo que muestra con los ejemplos de la observación de la cara y de los hombres que pasean. En el caso de Pascal, la pregunta sobre el conocimiento de la esencia del yo, se desplaza a la cuestión de por qué razón se ama a una persona en particular, ¿es posible amar la sustancia de una persona abstractamente?

A este respecto, Pascal además se plantea varias dificultades:

Primero se pregunta si las cualidades particulares constituyen el yo. Antes de que Nietzsche denunciara la «ficción gramatical» que impulsa a hacer del pronombre «yo» el principio de los pensamientos y actos ${ }^{22}$ (Magnard), Pascal se interroga sobre el fundamento de tal hipótesis. Un Pascal nostálgico se pregunta en otro fragmento, ¿acaso soy el mismo que hace veinte años? ¿Cómo amar el cuerpo o el alma sino por sus cualidades, por su mero aparecer? ¿Constituyen las cualidades, perecederas y cambiantes, al yo? La suma de interrogantes al respecto revela a Pascal que el conocimiento del yo no es claro ni distinto. El sujeto que piensa, el nuevo punto de Arquímedes desde el que Descartes edificará todo el edificio del saber, se manifiesta para Pascal inasible. La fortaleza del yo cartesiano es ilusoria.

En segundo lugar, lejos también de concebir al yo, según la expresión de Ch. Taylor, desvinculado, Pascal se pregunta por el yo y por «mí mismo» desde la intersubjetividad. Se interroga por las razones que hacen amar a una persona sabiendo que no podemos ubicar al yo. En otro fragmento, Pascal advertirá que la causa del amor es un «no se qué», capaz, sin embargo, de remover la tierra entera (L. 618).

En suma, Pascal se interesa por la irreductible individualidad, desde la perspectiva del amor. Con ello, avanza una filosofía de la afectividad y de la alteridad que resultará para él esencial. El yo no es algo abstracto, ni que se pueda concebir de un modo aislado. Son las relaciones interpersonales y los afectos, los apegos y carencias, los que constituyen la raíz profunda e inasible de uno mismo. No podemos representarnos desarraigados de la realidad de nuestro entorno y de los otros.

Así, el ordo amoris ${ }^{23}$ se revela de continuo como la clave del pensamiento antropológico y teológico de Pascal, el problema más serio, distante del orden racional y lineal de Descartes. Carraud defiende que la egología es sustituida por la agapología. Con ello, parece identificar el ser amado con el ser yo mismo. Porque el yo es amado o puede serlo, es o puede $\operatorname{ser}^{24}$.

\section{El Yo odioso: oposición de egocentrismo-desprendimiento}

La moral cartesiana trata por todos los medios de fortalecer el yo. En cambio, Pascal pone de manifiesto una asombrosa paradoja: cada uno quisiera ser el centro de todo, cuando en el conjunto de la reali- 
dad no es más que un punto entre infinitos puntos. De ahí, explicará Pascal (L. 597) que lo que llamamos «yo» tenga dos cualidades: es injusto en sí, por hacerse el centro de todo; y es incómodo para los demás, porque quiere someterlos. Odiar el propio yo, afirmación que desataba las iras de Voltaire y Nietzsche, implica cuestionar y distanciarse del amor propio, entendido como egoísmo.

«El yo es odioso. Vos, Miton, lo encubrís, pero por eso no lo suprimís. Sois, pues, siempre odioso.

- No, porque obrando como lo hacemos, cortésmente con todo el mundo, no hay motivo para que se nos odie.

- Eso es verdad, si no se odiara en el yo más que el desagrado que nos causa.

Pero sí le odio porque es injusto que se haga el centro de todo, le odiaré siempre.

En una palabra, el yo tiene dos cualidades. Es injusto en sí, pues se hace el centro de todo. Es incómodo para los demás, pues quiere someterlos; porque cada «yo» es enemigo - y quisiera ser tirano- de todos los otros. Suprimís la incomodidad, pero no la injusticia.

Y así, no lo hacéis amables a los que en él odian la injusticia. No lo hacéis amables más que para los injustos, que no encuentran en él a su enemigo. Y así, seguís siendo injustos, y no podéis agradar sino a los injustos» (L. 597).

Como Hobbes y Schopenhauer, para Pascal el egoísmo es la raíz de la injusticia y de la violencia que convierte la vida humana en pobre, brutal y devastadora. Como Agustín, Pascal reconoce en el hombre un fondo de maldad, un figmentum malum, que explica el odio recíproco. En realidad, cada uno quisiera ser un tirano para los demás, aunque ese fondo se oculta con buenas maneras y honestidad aparente, incluso con una falsa imagen de la caridad (L. 211). ¿Cómo romper ese círculo devastador?

Pascal contrapone el amor de sí con el amor al ser universal que exige descentramiento y experiencia de vaciamiento.
Si el amor propio es soberano, la justicia es irreal. Sólo liberándose de los deseos de dominación, se descubre la verdadera justicia y bondad. No hay victoria $\sin$ vencidos.

Odiar el yo significa para Pascal odiar el amor de sí, un amor preferente y desmedido de sí, un instinto que lleva a hacerse a sí mismo un Dios, a constituirse en centro (L. 978, L. 597). En lenguaje contemporáneo, el «amor propio» es un egocentrismo narcisista. Odiar el yo es odiar un amor usurpador que convierte al propio yo en bien supremo, en tirano de todos. Odiarse a sí mismo significa odiar una perversión: que una parte de la realidad se ame como si fuera el todo. Es una clase de ceguera propia de un corazón de piedra, que ignora el sufrimiento ajeno. Vencer el amor propio significa profundizar en la interioridad para hacerse capaz de amar el ser universal. Si se quiere hacer posible los sueños de bien absoluto, el hombre debe abrirse a la Trascendencia (L. 378).

Pascal apela al corazón «convertido». Un corazón de carne es un corazón compasivo que se abre a la realidad del sufrimiento ajeno, que experimenta como propio. Entonces, se descubre el buen uso del amor de sí.

Para Pascal, como para después Kierkegaard, el amor a los demás se realiza por mediación de Dios. Y a Dios accede por medio de Cristo, que hace ver en el otro alguien próximo, sufriente y capaz de bien, no a un rival. Solamente así resulta lo humanamente imposible: el deber de amar a los otros como hermanos, incluso a los enemigos.

\section{Los tres órdenes de realidad}

En la primera parte de su Apología de la religión cristiana, Pascal pensaba detallar las contradicciones propias del hombre sin Dios; la segunda parte de la Apología, superados los dos extremos: la soberbia y 
la desesperación, presentaría al hombre reconciliado. Las escisiones y conflictos de la condición humana descritas por Pascal, darían paso a un nuevo orden que restaura el equilibrio perdido.

Este es el sentido final de un nuevo anuncio: «nadie es tan feliz como un verdadero cristiano, ni razonable, ni virtuoso, ni amable» (L. 357), aspecto de su pensamiento que se suele ignorar ${ }^{25}$. Para Pascal la manifestación de Dios es histórica y está ligada a Jesucristo, mediador entre Dios y los hombres. Entonces el amor egocéntrico y malsano, da paso a una justa y sana estima de sí, al comprender que formamos parte de un todo: «... al amar al cuerpo se ama a sí mismo porque sólo tiene ser en sí, por sí y para sí» (L. 372).

El autor de los Pensamientos recupera la idea paulina del cuerpo místico de Cristo y se imagina «un cuerpo lleno de miembros pensantes». La imaginación es aquí un poder creador de sentido. La felicidad está entonces en consentir con la conducta del alma entera de la que forma parte, que «les ama más de lo que se aman a sí mismos» (L. 360). Todo es uno y: «el que se adhiere a Dios, es un solo espíritu con Él». Este es el orden de la caridad al que aspira la moral cristiana, una moral de generosidad y de unión, una fuerza creadora que redime y da vida. Desde ahí todas las cosas cobran una nueva luz.

La ruptura de planos en las que Pascal incide de continuo se explican por la existencia de tres órdenes de realidad cualitativamente distintos: los cuerpos, los espíritus y la caridad. Si Descartes insiste en la distinción entre los dos primeros órdenes, Pascal advierte en la distancia entre los tres. Por este motivo, se explica que la grandeza de unos sea invisible para los otros. Así, la grandeza de las personas de espíritu es invisible para los que buscan la grandeza en lo material, como los ricos o los reyes, que no miran con los ojos del espíritu. Al igual que hay quien no puede admirar más que las grandezas materiales, como si no las hubiese espirituales, otros no admiran más que las intelectuales, como si no las hubiera infinitamente más elevadas en la sabiduría. Pascal mantiene el principio de inconmensurabilidad y discontinuidad de los distintos órdenes de las cosas ${ }^{26}$. Las grandezas propias de un orden guardan proporción entre ellas, pero no con los otros órdenes.

«La distancia infinita de los cuerpos a los espíritus simboliza la distancia, infinitamente más infinita, de los espíritus a la caridad, porque ésta es sobrenatural.

Todo el brillo de las grandezas no significa nada para la gente que se ocupa de las investigaciones del espíritu.

La grandeza de la gente de espíritu es invisible para los reyes, los ricos, los capitanes, todos esos materialmente grandes.

La grandeza de la sabiduría, que no existe más que en Dios, es invisible para los materiales y a las personas de espíritu. Son tres órdenes de género diferente.

Los grandes genios tienen su imperio, su esplendor, su grandeza, su victoria y su brillo, y no tienen ninguna necesidad de las grandezas carnales, con las que no tienen relación. Se les ve, no con los ojos, sino con el espíritu. Es suficiente.

...Pero hay quienes no pueden admirar más que las grandezas materiales, como si no las hubiese espirituales. Y otros que no admiran más que las espirituales, como si no las hubiera infinitamente más elevadas en la sabiduría..

...Todos los cuerpos, el firmamento, las estrellas, la tierra y sus reinos, no valen lo que el menor de los espíritus. Porque éstos conocen todo eso, y a sí mismos; y los cuerpos nada.

...Todos los cuerpos juntos y todos los espíritus juntos y todas sus producciones, no valen lo que el menor impulso de caridad. Esto último es un orden infinitamente más elevado.

De todos los cuerpos juntos no sabríamos hacer surgir un pequeño pensamiento. Es imposible y de otro orden. De todos los cuerpos 
y espíritus no se sabría obtener un impulso de verdadera caridad; es imposible, y de otro orden distinto, sobrenatural» (L. 308).

La distinción de los tres órdenes, es una clave central ${ }^{27}$ en la argumentación de Pascal. No trata tanto de completar el dualismo cartesiano y definir las clases de sustancias, como de caracterizar los distintos órdenes de valores, o incluso lo que podríamos llamar estadios de la existencia como en Kierkegaard ${ }^{28}$. Para Descartes, el error está en seguir un procedimiento fallido, en un mal uso de la razón; para Pascal el error está en no advertir la distancia entre los distintos órdenes y la racionalidad y valores que les son propios.

Los tres órdenes se corresponden con tres clases de personas: los carnales o materiales (los mundanos), los doctos (los científicos y filósofos) y los santos o los perfectos cristianos. En cada uno de ellos domina una de las facetas del ser humano: en los primeros lo material, en los segundos la inteligencia, en los terceros el corazón convertido. Estos tres órdenes son gobernados por aquello que deleita a la voluntad (delectatio). Los materiales buscan la satisfacción en los placeres del cuerpo, los doctos persiguen la satisfacción de su curiosidad mediante su inteligencia, los terceros quieren satisfacer su corazón con la justicia y la caridad. A los ojos de unos, la vida de los otros es incomprensible, pues su jerarquía de valores es distinta. Esto explica que en cada orden haya a quienes se consideren los «superiores» del orden respectivo, que no son reconocidos como tales por los que están en un orden distinto. Así, los grandes genios que persiguen satisfacer su inteligencia, no son comprendidos por los que se orientan a los placeres. Lo mismo ocurre con los que buscan la grandeza en el orden de la caridad, pues no son aceptados por los que se dedican sólo a los bienes de la inteligen- cia. Son calificados de locos a los ojos del mundo.

Como para Erasmo, la suprema felicidad a la que aspiran los creyentes, el verdadero heroísmo y la santidad no es sino una especie de locura para los demás. Tres figuras representan los tres órdenes: el rey, Arquímedes y Cristo. El principio que organiza el orden superior es desconocido por los que están en un orden inferior, en cambio quien está en el orden superior percibe la diferencia de los distintos órdenes y la clase de racionalidad y de amor que en cada caso es aplicable. A los tres órdenes de realidad corresponden las tres facetas de la condición humana: el cuerpo, el espíritu o la inteligencia y el corazón. Corresponden al nivel sensible, inteligible y moral. Descartes, como Arquímedes, permanece en el segundo orden.

La corrupción, que afecta al conocimiento y a la voluntad, puede estar presente en los tres órdenes. Esto explica que se quiera dominar a los otros hombres, tanto en el orden del cuerpo (los tiranos), como por el espíritu (el principio de autoridad en las ciencias), como por el corazón (los falsos profetas). Pascal constata la enorme distancia que existe entre la devoción, sólo atenta a las formas, preceptos y ritos, y la auténtica bondad gratuita (L. 365). Es la distancia entre el cumplimiento de la ley y la caridad.

Fuera de las verdades demostrativas, que pertenecen al orden del espíritu, no hay verdad más plena que la caridad, el «ordo amoris». El orden de la caridad sobrepasa al orden de la inteligibilidad, a la razón instrumental del cartesianismo. Representa el punto de vista absoluto, a partir del cual se ordenan todos los puntos relativos. Esto explica el fragmento L. 926: "se hace un ídolo de la verdad misma, pues la verdad fuera de la caridad no es Dios, y es su imagen y un ídolo al 
que no hay que amar y adorar, y aún menos a su contrario que es la mentira».

Desde el orden de la auténtica caridad, fuente de todas las virtudes, el hombre se vincula de un modo limitado a los bienes finitos, corporales y espirituales y dirige su deseo infinito de bien y de verdad a lo sobrenatural y eterno. El amor a Dios se expresa en la caridad que es vínculo de perfección moral y restaura el orden y la armonía. Es un vínculo de fraternidad. Asigna a cada cosa su sitio. A su lado, las demostraciones sobre la existencia de Dios resultan superfluas. Se comprende de nuevo el sentido del fragmento: «Descartes: inútil e incierto».

El orden del espíritu - la ciencia y la filosofía- es preciso para descubrir verdades parciales y para reconocer las limitaciones, los desórdenes y las contradicciones de la vida humana. Permite descubrir ciertas verdades, tomar conciencia de la ignorancia y de los límites de la razón. Pero no hay que idolatrarlas. Pascal busca la apertura a otra verdad última que satisfaga el deseo de bien y de verdad plena y ofrezca un remedio a la escisión. Lo encontró en la experiencia de la originaria religión cristiana y en la ética de la caridad, entendida como un amor generoso y altruista, que asume el sufrimiento ajeno como propio. Es su punto firme de apoyo y de estabilidad.

Así, finalmente se comprueba que la experiencia religiosa de Pascal unifica su pensamiento y asigna su lugar preciso a la vida mundana, la ciencia y la fe. De ahí que viera en las pruebas cartesianas de la existencia de Dios, un mero instrumento para avanzar en el propio sistema (L. 1001).

Sin embargo, a diferencia de Descartes, que recomendó obediencia sin discusión a la autoridad eclesiástica o política, Pascal siempre consideró necesario discernir los límites en los que la sumisión a la autoridades estaba justificada. En su primera Carta a Charlotte de Roannez, indicaba que la corrupción podía habitar también en casas consideradas sagradas y en los libros de teología.

Para Pascal, recuperada la auténtica vinculación con Dios, por medio de la caridad, la sociedad encuentra entonces un fundamento sólido. Se vincula a la justicia absoluta. Sin Dios, no es posible alcanzarla, pues el egoísmo divide y enfrenta de continuo a los hombres. Con Dios: «dos leyes bastan para regir toda la república cristiana, mejor que todas las leyes políticas» (L. 376). El amor a Dios, por medio de Cristo, posibilita el amor al prójimo y así la humanidad se reconcilia también consigo misma. Es el anuncio de un nuevo modelo de humanidad. Esta es la última perspectiva: «Jesucristo y San Pablo siguieron el orden de la caridad. Este orden consiste en la digresión sobre cada punto con relación al fin para mostrarlo siempre (L. 298).

El orden del corazón es diferente del recorrido progresivo de la razón ${ }^{29}$. Las reflexiones de Pascal sobre los temas más diversos desembocan en el descubrimiento de ese orden último. Todos sus esfuerzos y recursos se dirigen a inquietar intelectual y afectivamente a su lector, a desmitificar y a denunciar la idolatría reinante. Siempre repite los mismos temas vistos desde distintos ángulos, en una retórica de la repetición. Es la lógica de la digresión, en virtud de la cual todas las cuestiones analizadas están impregnadas de las mismas claves. Es el estilo que corresponde al orden del corazón y que invita a la búsqueda interior y espiritual. Así, la forma de la obra coincide con el fondo de la obra: se muestra lo que se ama, no se demuestra. El luminoso orden de la razón se complementa con el misterioso orden del amor.

El interés de la filosofía de Pascal no está en su acumulación de las contradicciones humanas que conducirían de nuevo 
al pirronismo (L. 691), sino la articulación de la razón y el sentimiento, el saber y la fe. Pascal fue un hombre de síntesis y de distinciones que alertó sobre el peligro de reduccionismos de cualquier tipo y la necesidad de discernimiento y coherencia. Sólo el funcionamiento armonioso de la razón y el corazón, del espíritu geométrico y el de finura, conducen a una ciencia y a una sabiduría humana.

Aunque Pascal admiró los descubrimientos de la nueva ciencia y del humanismo renacentista, no se dejó deslumbrar por ellos. Si bien admiró algunos aspectos del pensamiento cartesiano, se alejó de su proyecto de relegar la teología. Como Erasmo, describió la locura del mundo. Vio el fondo oscuro e ingobernable del corazón humano y la falta de estabilidad en la vida.

De ahí su diagnóstico: sin Dios, el ser humano, constitutivamente ambivalente, no renuncia a su egoísmo y construye nuevos absolutos. No hay bondad natural. Abandonados a sí mismos, los hombres acaban devorándose. El discurso de Pascal sobre la amplitud de los males, recuerda a Job y anticipa a Schopenhauer. Sus preguntas sobre las consecuencias de un mundo sin Dios donde todo esté permitido, a Dostoievski. Como él, piensa que cuando no es posible demostrar racionalmente nada de un modo definitivo, la experiencia del amor ayuda a convencerse de que otro mundo es posible.
Para terminar, quisiera insistir que, en todo caso, Pascal debe ser situado en su propia época para ser comprendido. En un momento histórico en el que la ciencia comenzaba a constituirse como paradigma, advirtió de sus límites. En un tiempo en el que la Iglesia tenía un gran poder, denunció que había muy pocos cristianos auténticos. Siglos después, Kierkegaard también lo hará.

Es cierto que su trasfondo jansenista y su agustinismo extremo incomoda a sus lectores y que un abismo separa al exegeta contemporáneo de un biblista del XVII. Es verdad que parece olvidar los aspectos positivos de la existencia. Pero como Unanumo y Aranguren supieron entender, sus escritos y su "pathos existencial y vital», su interés por las cuestiones esenciales y aparentemente insolubles, le convierten en un clásico que, precisamente por ello, aún ahora sigue dando qué pensar.

En definitiva, fue un maestro de la inquietud y de la desmitificación, pero también de la esperanza. Aspiró a lo Trascendente y eterno, por entender que eleva al ser humano. Frente a la indiferencia, invita a la praxis y al compromiso; frente al desencanto a perseverar en la búsqueda y la esperanza. Y es así, como el drama de la modernidad naciente, la dialéctica entre un racionalismo reduccionista y un emotivismo ciego, es vivida por Pascal de un modo personal.

\footnotetext{
1 El contenido de este artículo, que se vincula con el Proyecto de I+D del Ministerio de Ciencia e Innovación: «Fundamentos filosóficos de la idea de solidaridad» (FFI 2998-05104), fue objeto de una ponencia más extensa en las VII Jornadas de Diálogo Filosófico, celebradas en Salamanca, 21-24 octubre 2009, con el título: «La dialéctica moderna del racionalismo y el antirracionalismo».

2 La revista francesa Le Point en su número de agosto de 2009 dedica un interesante artículo a la ac-
}

tualidad de Pascal: Roger Pol-Droit, «Pascal. L'effrayant génie», pp. 59-66.

3 Véase al respecto el capítulo que Gouhier dedica a Pascal y Descartes en: H. Gouhier, Blaise Pascal. Conversion et apologétique, Paris, Vrin, 1986, p. 167.

4 Pascal y Descartes estuvieron acompañados por un amplio grupo de personas. Pascal, entonces enfermo, quiso que Roberval le acompañara para que pudiera detallar a Descartes el diseño y funcionamiento de su máquina aritmética. Descartes visitó de nuevo a 
Pascal el día siguiente y preocupado por su enfermedad le facilitó consejos médicos.

5 Pascal siguió ocupándose de temas científicos hasta 1658 , cuando resolvió un problema geométrico sobre una curva llamada «ruleta» o «cicloide» que fundó el cálculo infinitesimal. Ese mismo año organizó un concurso ofreciendo un premio al sabio que resolviera el problema.

${ }^{6}$ La numeración de los fragmentos se realiza conforme a la edición de Loius Lafuma (L.)

7 Pascal había escrito antes: «Descartes inútil y cierto».

${ }^{8}$ Los trabajos matemáticos de Pascal versaron sobre la aritmética, la geometría y las probabilidades; sus trabajos como físico se dedicaron al estudio y experimentación sobre el vacío y el equilibrio de los líquidos; como ingeniero se dedicó al diseño de la máquina aritmética. Ello revela no sólo la amplitud de su genio, sino también su atención a lo concreto y práctico.

9 Cfr. Catherine Chevalley, Contingence et probabilités, PUF, Paris, 1995, p. 7.

10 Para Pascal la investigación matemática y física debe estar libre de supuestos metafísicos, en especial de aquel que hace de la extensión el atributo de la sustancia material, pues supondría a priori negar la admisión del vacío. Tampoco cuenta con la distinción real de las dos sustancias, ni con la veracidad divina. Le interesa conocer, más que la esencia de los objetos de las matemáticas o de la física, sus propiedades, relaciones y funciones (Cfr. Hélène Bouchilloux, Pascal, Vrin, Paris, 2004, p. 4).

11 Cfr. Ph. Sellier, Pascal, Paris, Editions Points, 2009, pp. 12-13.

12 «Incomprensible que Dios exista e incomprensible que no exista, que el alma exista con el cuerpo, que no tengamos alma, que el mundo haya sido creado, que no lo haya sido, etc., que el pecado original exista y que no exista» (L. 809).

13 Se calcula que aproximadamente dos terceras partes de los fragmentos incluidos en los Pensamientos estarían destinados a este propósito. Cfr. la Sección I (Papeles Clasificados) de los Pensamientos, según las ediciones que siguen el orden de las copias del manuscrito original (Louis Lafuma, M. Le Guern).

${ }^{14}$ Los fragmentos incluidos en la primera serie insisten en que hay que hacer a la religión cristiana digna de ser amada y admirada: amable y venerable.

15 Él mismo advertía que su organización de los pensamientos era nueva: "¡Cómo si las mismas palabras no formasen otro cuerpo de discurso a causa de una disposición diferente, igual que las mismas palabras forman otros pensamientos, por su diferente posición!» (L. 696).

16 Hay también en muchos fragmentos una alusión a la delectatio y el amor sui de San Agustín.

17 «Todo lo que está en el mundo es concupiscencia de la carne o concupiscencia de los ojos u orgullo de la vida. Libido sentiendi, libido sciendi, libido dominandi. ¡Desdichada la tierra de maldición que estos tres ríos de fuego abrasan más que riegan! ¡Bienaventurados los que estando en estos ríos, no son sumergidos, ni arrastrados, sino que permanecen inmóviles, firmes sobre ellos, no de pie, sino sentados, en un asiento bajo y seguro, del que no se levantan antes de la luz, sino después de haber reposado en paz, y tienden la mano a quienes les debe levantar, para mantenerles de pie y firmes en los pórticos de la Santa Jerusalén, donde el orgullo no les podrá ya combatir ni abatir, y que, sin embargo, lloran, no por ver pasar a todas las cosas perecederas que estos torrentes arrastran, sino por el recuerdo de su querida patria, de la Jerusalén celestial, de la que se acuerdan sin cesar a lo largo de su exilio!» (L. 545).

18 Descartes estaría muy próximo a los estoicos a los sabios que quieren controlar racionalmente las pasiones y buscan la serenidad en el puro conocimiento.

19 Así es calificado por V. Carraud, Pascal et la philosophie, Paris, PUF, 1992 (p. 324). Carraud realiza un estudio pormenorizado y muy sugerente de este fragmento, algunas de cuyas reflexiones se recogen aquí (pp. 316 y ss.).

${ }^{20}$ El pasaje de Descartes precisaba: «si por azar observara desde una ventana los hombres que pasean por la calle... «(IX-1,25,12-19).

21 Recordemos que esto es lo que Descartes se planteaba después de descubrir la primera evidencia: «soy, existo». A la pregunta ¿qué soy yo?, responderá soy «una cosa que piensa».

22 P. Magnard, Pascal ou l'art de la digresión, $\mathrm{Pa}-$ ris, Ellipses, 1997.

23 «El corazón tiene su orden, el espíritu el suyo que procede por principio y demostración». No se puede probar lo que debe ser amado exponiendo con orden las causas del amor. Sería ridículo, como observa en el fragmento (L. 298).

24 V. Carraud, p. 323.

25 Se desarrolla en las Series: «Moral cristiana» (XXVI) y «Pruebas por Jesucristo» (XXIII), de la Sección I (Papeles clasificados) de los Pensamientos. La teología de Pascal es cristocéntrica y ahí la dureza de su lenguaje desaparece.

26 En la Sommation des puissances numériques, Pascal había subrayado la heterogeneidad de los diferentes géneros. Por adición de puntos, no se llega nunca a una línea, por la adición de líneas no se llega a una superficie.

27 Cfr. J. Mesnard, «Le thème des trois ordres dans l'organisation des Pensées», en Pascal. Thématique des Pensées, L. M. Heller et I. M. Richmond dir., Paris, Vrin, 1998 y T. Pavlovits, Le rationalisme de Pascal, Paris, Publications de la Sorbonne, 2007, p. 193.

28 Cfr. P. Magnard, p. 57.

29 J. Mesnard, Les Pensées de Pascal, pp. 176178. 